\title{
गHP
}

\section{Cultural Cartographies: The Logic of Domination and Native Cultural Survival}

\author{
SHARI M. HUHNDORF, \\ SCOTT L. PRATT \\ University of Oregon
}

D'Arcy McNickle's novel Wind from an Enemy Sky (1978) begins: “The Indian named Bull and his grandson took a walk into the mountains to look at a dam built in a cleft of rock, and what began as a walk became a journey into the world" $(1995,1) .^{1}$ As with most journeys, and as distinct from wanderings and well-practiced travels to familiar places, the journey portrayed by McNickle depends upon maps of various kinds to chart and negotiate unknown territory. In the novel, McNickle describes "maps of the mind" that provide strategies for comprehending and negotiating the world, often in vastly different ways. Specifically, in Wind, these are conceptual maps shaped by cultural histories and experiences, and they determine the dynamics of intercultural encounters, the focus of the story. We will argue that even as McNickle presents a chronicle of contact and communication between Native American and European American people, he offers a theoretical assessment of the different kinds of mapping used at these points of contact and their consequences. McNickle's narrative centers on the issues of colonialism, Native American identity, self-determination, and cultural survival. Alternative ways of mapping the world both create and provide resolutions to these problems. Historically, maps have been essential resources in the process of colonialism; knowing indigenous people meant mapping them in locations relative to the colonizers. With maps came the possibility of exploitation, dispossession, and assimilation. McNickle's use of maps as metaphors evokes this violent history. But even as these contending colonial maps lead to tragedy, the story dramatically proposes

The Journal of Speculative Philosophy, Vol. 14, No. 4, 2001.

Copyright (c) 2001 The Pennsylvania State University, University Park, PA. 
an anticolonial approach to mapping that is grounded in Native American thought and committed to cultural continuity rather than destruction.

McNickle presents at least three kinds of mapping in the course of the novel. The first attempts to provide a totalizing and static portrait of the world, subsuming all diversity into a single epistemological framework. The second more modestly tries to map Indian Country alone, in isolation from the colonizing European American culture, and it defines Nativeness solely in terms of its difference from European America. Both maps, however, are colonial because they assume the power to define Native people from outside, usually as unchanging and inferior to European Americans, and to govern them. These two maps, McNickle argues throughout the story, undermine the possibility of Native sovereignty and, thus, Native cultural survival despite the sometimes benevolent intentions of those who use them. A key to understanding both the structure and problems of these colonial maps is found in twentieth-century Anglo-American philosophy, specifically in Bertrand Russell's analysis of the limitations of logic and knowledge. Like McNickle, Russell challenges the possibility of totalizing maps and identities. Instead, he adopts a more modest alternative that parallels McNickle's second map, displaying both its strengths and its weaknesses. In the novel, McNickle shows the failures of this map as well and proposes a third alternative that is both functional and flexible, one aimed at finding means to specific ends rather than envisioning a comprehensive portrait of the world. This map rejects the colonial power to define and to govern from outside in favor of the ability to make and use nontotalizing maps within a local, changing context as a means of cultural survival and self-determination. McNickle's conception of maps and their purposes is critically important because of its implications both for philosophy and for anticolonial movements. Wind from an Enemy Sky, as we read it, thus presents an examination of these contending approaches to mapping - of ways of comprehending and negotiating the world - alive in twentieth-century philosophy. However, McNickle extends conventional philosophical analysis by showing the concrete and often colonial effects of particular ways of knowing the world. As a result, he points out, those who would successfully resist colonial domination must understand its logic in order to avoid repeating its patterns.

Wind from an Enemy Sky begins with two tragic events that relate to the dynamics of colonialism in the novel. It is the nature of these events, and various characters' reactions to them, that reveals the three conflicting "maps of the mind" that manifest themselves in the actions that drive the narrative. As one character observes, these different maps are a crucial source of the political and cultural conflicts in the story: "The problem is communication.... The answer, obviously, 
is that we do not speak to each other-and language is only part of it. Perhaps it is intention, or purpose, the map of the mind we follow" $(1995,125)$. The novel presents a portrait of these various maps and illustrates their concrete consequences. For McNickle, ways of seeing the world are never purely abstract. Rather, they are always linked to lived events, and at times in the story these events are devastating.

Set in the 1930s, the novel opens with the (fictional) Little Elk tribe's discovery of a cataclysm: the construction of a dam by white developers floods a lush valley on former tribal land, long known by the Little Elk people to be a "place of power"-a sacred place, in other words, which had long played an important role in the culture of the tribe and thus commanded care and respect. The very existence of the dam, then, violated Little Elk belief systems. But it carried other implications as well. McNickle likely drew inspiration for this scene from actual events that occurred around the time he began the novel, ${ }^{2}$ the dambuilding enterprises on Indian reservations characteristic of the development projects of the Roosevelt era. "Progress," readers soon learn, had similarly compelled the construction of the Little Elk dam, which diverted water to farm lands owned by white homesteaders. As the story unfolds, links between colonial history and this present catastrophe become increasingly clear. These homesteaders had gained title to Indian lands as a consequence of the General Allotment Act of 1887 , a policy that defied treaty obligations and divided reservation land into individual allotments. Characteristic of the colonial efforts of the United States to transform Natives into "civilized" Americans, the Act effectively shattered traditional social structures and attempted to transform Natives from communal occupants of collective property into individual farmers, that is, to acclimate a "primitive" people into a "higher" stage of development as propertied farmers. ${ }^{3}$ The Act obviously benefited non-native people. Once tribal members had received the requisite land, the government (represented by the local Indian agent) opened vast tracts of "surplus" reservation land (often the choicest parcels) to white settlement. In the novel, the Little Elk dam, which supplies these homesteaders with water for irrigation while drying up the Indians' water sources, is merely the latest in a series of appropriations of Native resources and attacks on traditional ways of life. The building of the dam also reflects on the Little Elk people's current situation. Confined to the reservation and under the control of a host of colonial officials, their inability to resist the building of the damindeed, their virtual lack of knowledge of its existence until it was too latepoints to the overall powerlessness of the tribe in the colonial era. The conflicts embedded in this event are at the crux of the novel. What, exactly, are the mechanisms of colonialism? What logic do they follow? And, ultimately, McNickle asks, how can we escape them?

The logic of these particular events is the product of the first map of the mind in the novel, the map that presents all of the world in a single picture with Europe and things European at its center. In McNickle's story, following a map that defines the Little Elk as inferior to European-derived ideals of "civilization," 
government agents attempt to replace Native ways with European American culture-in other words, to make "them" like "us." Efforts to undermine traditional practices and promote economic development, as well as aggressive educational programs, all pivoted on the expectation that differences apparent in Native people could be understood in terms of a universal conception of human nature, a map against which aspects of Native culture could be measured. Different practices could and should be eliminated, or at least moderated. Historically, this process of annihilating Native differences rendered possible and "justified" the appropriation of Native land and other resources. The entire project, however, depended finally on a central logic that imagined it had the ability to comprehend successfully the world on its own terms and thus to command conformity. The problem faced by this colonial "map of the mind" in the context of McNickle's novel-its failure to recognize and engage difference-points to the integral relationship between epistemological and colonial practices and parallels a central problem in twentieth-century Anglo-American philosophy: the problem of completeness and the paradoxes of self-reference.

Even as McNickle recognized the problem of colonial maps in his work in the 1930s, Russell had previously explored a central problem of their logic in 1902, and his insight became a turning point in the history of European and American philosophy. Rather than being simply an abstract concern for philosophers of mathematics and logic, the problem reflects on McNickle's analysis of alternative approaches to mapping by calling into question what and how we know. Inspired by early developments in the philosophy of mathematics, Russell had set out to propose his own complete formulation of the principles of mathematics. By 1902, he was well along in what he thought would be the definitive work on the philosophy of mathematical logic when he came across a problem. As he reports it, the problem emerged as he tried to work out the implications of Cantor's proof that there can be no greatest cardinal number (Russell 1903, 101). The proof turned on the conclusion that for any given number, there is always a greater one. If this is true for numbers, Russell worried, a similar principle might lead to a contradiction in attempts to formalize completely mathematics through set theory. According to the general set theory Russell was using, sets can be formed by objects that share any well-defined property so that, for example, multiples of 2 and multiples of 19 constitute sets. Sets can contain other sets, as in the case of the set containing two sets, the set of even numbers and the set of odd numbers. One possible set containing other sets is the one that contains all and only those sets whose members do not include themselves. For instance, the set of all human beings does not contain itself since it contains only human beings and no sets at all. Sets that do not contain themselves as members are called impredicative sets.

The problem emerges when we ask whether this set containing all and only impredicative sets also includes itself. If it does not contain itself, then, of course, it is an impredicative set and so, in blatant contradiction, must contain itself. But if it does contain itself, then it cannot be an impredicative set. It follows from 
the contradiction that the set containing all and only impredicative sets is not itself impredicative. And if it is not impredicative, then by definition it does contain itself and so, since all sets it contains are impredicative, must be impredicative after all. Both answers led to contradiction and so something was very definitively wrong. If set theory is necessary to formalize arithmetic, but the rules of set theory lead inevitably to contradiction, then attempts to "know" math by giving all of its rules were in trouble. Despite the apparent insignificance of the problematic case, that is, an unlikely set in the midst of an otherwise useful theory, the disaster for philosophy of logic, mathematics, and epistemology was enormous. Unless principles could be found to eliminate the contradiction, Russell concluded, all general accounts of deduction become impossible $(1956,64)$.

For philosophers made confident by the successes of science and the weakening hold of doctrinal religion on academic philosophy, Russell's paradox became a crucial problem. For philosophers like Gottlob Frege, the process of completely mapping arithmetic through formal principles was simply part of the general expectation that comprehensive knowledge of the world was at least possible, if not likely. ${ }^{4}$ To find what seemed to be an inherent limitation at the very center of so basic a project threatened the logic that supported human knowledge. When Frege learned of the paradox in a letter from Russell, he replied, "Arithmetic totters" (qtd. in Quine 1976b, 11) and eventually gave up what he had expected to be a final formulation of the foundations of arithmetic. The logic of Frege's effort is instructive because his project was in a crucial way an abstract version of the process of mapping illustrated in Wind from an Enemy Sky that attempts to present a fixed and complete picture of the entire world, including the relationship between Native America and European America. Just as Frege's theoretical effort failed of its own logic, McNickle argues, its lived version at the intersection of Native and non-Native worlds must necessarily fail as well.

In McNickle's novel, most of the European American characters share a commitment to a kind of Fregean mapping of the world-complete and final-where Native people are forever "savages" and Europeans are forever the universal "ideal." Following this map and thus convinced of the necessity of their own dominance, these characters wreak destruction on Native people and their land. Appropriating the land and diverting the water is only part of the problem. The colonizers also convert Little Elk land into farms, disempower their leaders and replace them with U.S. government officials, and educate their children in white ways. McNickle evokes here the motto of General Richard Henry Pratt, mastermind of the boarding school policy designed to assimilate Native children: "Kill the Indian and save the man." The building of the dam provides a critical example of this process. For the Little Elk people, the place where the dam had been built was a "holy place," a "place of power" to be respected. "Be careful what you think. . . . Keep your thoughts good. . . . Don't have angry thoughts here" (1995, 5-6), the Little Elk people instructed their children. The European Americans, however, saw the place in terms that reduced it to a convenient 
resource for white ranchers. Whatever the Little Elks might have thought about it, their alternative meanings and purposes could only be superstitions and myths supervening on an otherwise profitable topography. For McNickle, the particular illustrates the general. Over and over again in colonial history, in advancing their own goals in the name of universal progress, European Americans heedlessly disregarded and destroyed aspects of Native Americans' physical and cultural worlds. In the novel, the death and destruction that stem from this colonial map of the mind both generate the lived contradictions of the logic of colonialism and show the potential of the Native alternative.

The construction of the dam leads inevitably to the second tragic event in the novel: the killing of Jimmy Cooke, a maintenance worker at the dam. This event demonstrates the consequences of the first map of the mind and its utter failure to comprehend difference. It is Pock Face, a young man of the Little Elk tribe, who travels to the dam and shoots Cooke after observing the turmoil brought to the tribe by the building of the dam. The shooting brings the two cultures into immediate and violent conflict. Mistakenly confident in his own ability to understand the situation and oblivious to Little Elk perspectives, the local sheriff, Sid Grant, relentlessly persecutes the entire tribe for the murder. His power testifies to the government's ability to impose its own system of justice while excluding the Indians' markedly different beliefs and practices. For the Little Elk people, Cooke's murder is not a murder at all: "Killing the water" (by building the dam) was "an unnatural distuption of a functioning universe, a kind of crime against life" $(1995,210)$, an act meriting retaliation. Nonetheless, the entire tribe undergoes a series of ordeals at the hands of the sheriff, as well as the Indian agent, Toby Rafferty, as the state seeks to prosecute Cooke's killer.

Despite his association with Sid Grant in prosecuting the murder of Cooke, Rafferty in fact embodies the second map of the mind in McNickle's story. He is presented as a European American different from both Grant and Rafferty's predecessors in the office of Indian Agent. As McNickle describes him, he is "a new man in Indian affairs" and his appointment "was announced as a repudiation of the military-political-missionary tradition that had prevailed in the past" (33). ${ }^{5}$ As part of the reform movement, Rafferty recognizes (to a limited degree, at least) the humanity of the Little Elk people and the value of some of their traditional practices. Also, like most reformers, he professes genuine sympathy for Native peoples and their plight. In the story, he continually mediates between Sheriff Grant (who practices the old, combative style of dealing with Indians) and the Little Elks, attempting to ease for them the ordeal of the murder investigation. He also develops a great affection for some of the tribe's members. However, a kind of paradox emerges in Rafferty's behavior, one that resonates with the contradictions inherent in the reform movement. Was this "new" style, McNickle queries, really so different from the old one?

This contradiction in Rafferty's treatment of the Little Elks becomes manifest in an encounter early in the novel when the agent confronts a dilemma: whether or not to help the Indians find and return a medicine bundle, a traditional 
object of spiritual power that a member of the tribe had surrendered to a missionary years before. Baffled, Rafferty consults Doc Edwards, the agency physician, about what he should do: "You can't answer these things right off," Rafferty explains, "What is it? How important is it? What happens if it comes back? Do we scrap all our ideas about improving their way of living, let them do a flipflop back to the past?" The agent's response to the request is revealing: patronizingly, he believes that it is he, Rafferty, rather than the Indians, who should decide what is best for the Little Elk people. Edwards, by contrast, urges the agent to rely on the Indians' own judgment: "Old Henry asked you something he considers important. After all these years of doing what the white man said was important, you have to stop and try to figure out whether he knows what he's doing. Don't you suppose he's already done a lot of thinking about it?" Appearing, however briefly, to recognize the problems inherent in his own position of authority, Rafferty responds: "If these people don't need what a white man has to offer, then we should all get out" (37-38). But the agent doesn't "get out." Ultimately, he takes up the Indians' cause and aids in their quest for the bundle, but his initial reticence reflects attitudes that carry through the rest of the story. Throughout the novel, he otherwise acts the part of the Indian agent, making on behalf of the government key decisions that affect the Little Elk peoples' lives and encouraging them to work toward their own "self-improvement" (i.e., assimilation). He presses them, for example, to take up farming, an integral part of the assimilation policies of the late nineteenth and early twentieth century. However sympathetic toward the Indians Rafferty may be, his exercise of power remains ensconced in the dynamics of colonial power he seeks to reject.

Rafferty's position parallels the workings of government policies during the late nineteenth and early twentieth century, the years leading up to and including the reformist era that provide the novel's historical context. Even as the government tried to instill individualism in Native communities through the 1887 Allotment Act, the effort in practice disempowered and fragmented entire communities. As the Meriam report (1928), which helped to establish the reform movement, explained it, "It almost seemed as if the government assumed that some magic in individual ownership would in itself prove an educational civilizing factor, but unfortunately this policy has for the most part operated in the opposite direction" (qtd. in McNickle 1973, 92). The reform movement of which Rafferty was a part rejected the old perspective and committed to the view that "freedom of choice is an essential ingredient of a democratic society, a freedom that cannot be exercised unless true alternatives are available" (93). As a result, Rafferty and those like him adopted a "task to help Indians meet the myriads of complex, interrelated, mutually dependent situations which develop among them, according to the very best light [the reformers] could get on those happenings" (Report of the Commissioner of Indian Affairs, qtd. in McNickle 1973, 93). But because individualism, private property, and democracy were inimical to most traditional social structures, these efforts in the end proved destructive to communities already shattered by colonialism. Whatever their intentions, the reform- 
ers' commitment to "helping" Natives by forcing values upon them further demoralized a dispossessed people struggling to survive centuries of genocide. What was missing was the Native voice, the power of Native peoples to make determinations about their own lives from within their communities.

Marking a distinct parallel between McNickle's narrative and the philosophical issues raised by the limitations of formal systems, Rafferty tries to carry out in practice the kind of radical revision of the old logic undertaken theoretically by Russell in light of the paradox he discovered. Not long after he published his findings, Russell determined that the problem was one of a range of paradoxes stemming from self-reference. In 1908, Russell himself reviewed the various versions of the problem identified after the initial publication of his set theoretic version in $1903 .{ }^{6}$ Taken together, all of the versions shared a common element of self-reference. Specifically, the problem with impredicative sets is the result of rules that allow sets to refer to themselves. When the question arises as to whether or not a set of impredicative sets is itself impredicative, a contradiction follows easily.

Behind the paradox, Russell concluded, is a problem of mapping, that is, a problem of how one set of ordered relations is mapped onto another. When the mapping includes a totality, that is, all the relations including those involved in the mapping itself, a paradox emerges. Russell illustrates this close connection between the problems of the paradox and the relations of mapping in his 1919 Introduction to Mathematical Philosophy. Here the problem of self-reference is introduced through an example he attributes to Josiah Royce:

One of the most striking instances of reflexion is Royce's illustration of the map: he imagines it decided to make a map of England upon a part of the surface of England. A map, if it is accurate, has a perfect one-one correspondence with its original; thus our map, which is part, is in one-one relation with the whole, and must contain the same number of points as the whole, which must therefore be a reflexive number. Royce is interested in the fact that the map, if it is correct, must contain a map of the map, which must in turn contain a map of the map of the map, and so on ad infinitum. (80)

Cantor's proof that there is no greatest cardinal number is the abstract analogue of Royce's mapping case. As Quine summarizes, Cantor's theorem establishes that for every class, even every infinite class, there is a larger class: the class of its subclasses $(1976 \mathrm{~b}, 15)$. In the mapping case, if the class in question is some territory to be mapped, its subclasses will include at least all of the things in the territory to be mapped and all of the corresponding elements of the map. So far, there is no paradox. However, as Quine observes, when the class in question includes everything, then a version of Russell's paradox follows directly (15). In this case, if everything includes the map and its territory, Cantor's theorem leads to the inevitable conclusion that, in addition to the map and its territory, there must be a still larger class that permits a still larger map, including, in effect, 
more than everything. As Russell put it following an unnamed Chinese philosopher, "[A] dun cow and a bay horse makes three things: separately they are each one and taken together they are another, therefore they are three" $(1956,260)$. If we expected a map to be accurate in the sense Royce suggests, we now know that it cannot be. Even if we expand the class of the map and its territory to include the map, its territory, and its connection (a map of the map and its territory), the problem begins again with the demand for still another map to encompass the new map and its object. In short, the very nature of mapping seems to guarantee that an accurate map of any totality will be impossible so long as the map is included in what is being mapped.

The consequence of this abstract critique is, as Russell recognized, a concrete limitation on mathematical logic and, by extension, on how human beings know the world. Apparently, the very nature of the process of mapping is such that when completeness is demanded, it cannot logically be achieved. Russell recognized the significance of the problem (though perhaps not its social consequences) and spent much of his long career attempting to solve it. Most of his attempts to do so followed the approach he took in a 1908 paper, "Mathematical Logic as Based on the Theory of Types." What is common to all of the paradoxes of self-reference, he argues there, is the common assumption of a totality such that, if it were legitimate, it would at once be enlarged by new members defined in terms of itself $(1956,63)$. In each case, the paradox is generated by an unrestricted notion of all: for Russell's and Cantor's paradoxes, the issue is an unrestricted reference to all sets; for the map paradox, everything in a certain geographic region. In order to avoid such paradoxes, Russell concluded that the objects of explanatory propositions must have definite boundaries so that anything that involves the object as a whole is not itself included in it. He expressed this conclusion as a rule: "Whatever involves all of a collection must not be one of the collection." The rule, which he calls the vicious-circle principle, is also expressed in the following manner: "[N]o totality can contain members defined in terms of itself" $(63,75)$. In short, the paradoxes in question can be defused by excluding the cases that generate them. Russell's paradox is prevented by declaring the set of all and only impredicative sets as illegitimate according to the vicious-circle principle. The map paradox is prevented by declaring meaningless the idea that a map can be enclosed in its territory and still be accurate. While the technical implications of Russell's conclusion lead to his theory of types, the more general implications are that attempts to arrive at complete accounts of aspects of the world must be pursued in ways that are nonreflexive. Accounts of the world will necessarily leave out self-reference, and the best point of view from which to construct any complete map will necessarily be outside the territory to be mapped.

Russell's solution implies the second kind of map, which recognizes the limits of the attempt to map everything but retains, in a crucial way, the power to map some things outside of itself completely. In Wind from an Enemy Sky, Rafferty's position follows this second map of the mind. From his office at the 
agency, Rafferty looks out upon Native America, however benevolently, from a position outside of it, a position that thus articulates colonial power. His aspirations to "aid" Native peoples by helping them to assimilate depend upon the misguided notion that he is in the best position to understand the Indians and decide what is best for them. Even though he rejects the first map, which assimilates Native peoples into a single progressive humanity regardless of the Native perspective, he accepts the more limited view that the Little Elk can be known and governed from a perspective outside the tribe. Thus, Rafferty rejected one colonial map, yet he retained a key feature of the first colonial map: the view that Native people themselves are not in a position to determine and respond to their own problems. As McNickle put it in a 1966 article, under the reform movement, the government made little effort to listen to Native concerns: "The complaints were real, but they conveyed no sense of an 'Indian' dialectic of involvement in their own fate" (276).

In this way, Rafferty's position resonates with Russell's response to the paradoxes. Despite its problems, the revisionary element of this response should not be understated. Even as attempts at totalizing theories, such as those proposed by the idealists of Russell's time, became increasingly suspect, the implications of what Russell learned from the paradoxes become a part of what constituted the acceptable background for new theories of logic, science, and knowledge. In light of Russell's findings, philosophers such as Quine came to conclude that we must expect to find not grand unifying theories, but rather limited accounts that address particular regions of the world. And, yet, even as Russell and later Quine undermined confidence in comprehensive theories, the resulting point of view, or better, the resulting approach to mapping implied in the response to the paradoxes of self-reference had another effect as well. Even as we must set aside attempts to know or explain everything, our attempts to know something must nevertheless proceed from a vantage point outside what we wish to understand. While Russell's denial of totalizing accounts amounts to a kind of anticolonial way of thinking about knowledge, it retains a colonial character in that it maintains the power to define its objects from the outside without reflecting on its own position. ${ }^{8}$

The third map of the mind, which opposes the colonial leanings of the first two maps, originates in McNickle's novel in traditional Little Elk ways of being in the world. It is different from the first and second maps of the mind in several ways: it renounces any aspirations to comprehend the world in terms of a single model and, as a result, it eschews the exercise of power, opting instead to engage difference rather than to annihilate it. It is, more accurately, not a map by itself, but a process or strategy for making maps that responds to changing circumstances. Unlike the first and second maps of the mind, which see the entire world in relation to an outside perspective, this third map of the mind involves crossing cultural borders and acknowledging the right to self-determination. This is most obvious in the novel in the ways two Indian characters, Son Child (also known as The Boy) and Antoine, engage the dominant European American society in 
the story. Son Child is a tribal member who works at the agency under Rafferty, and Antoine is the grandson of the Little Elk leader, Bull. Like Rafferty, both characters attempt to mediate between the tribe and the white world in the disputes over the dam and the murder. Unlike Rafferty, though, they are successful in their efforts in part because they understand both the Little Elk world and the European American world from the inside. Both are characters who, out of necessity, have repeatedly traversed the boundaries between cultural worlds. They attended Indian boarding schools and, in so doing, learned to understand the European American "map of the mind." At the same time, however, they remain committed to the welfare of the tribe as a distinct entity. While Antoine became fully reintegrated into the Little Elk community after his return from school at the story's beginning, Son Child opted to work at the agency under Rafferty. However, as he proves over and over again, his loyalties lie with the Little Elk people, and his position in the colonial government actually works to their advantage as he repeatedly intervenes on their behalf in the matter of Cooke's murder. In the novel, his relationship to the community is critically important. While both characters learn to negotiate the broader world, they use these skills on behalf of the Little Elk tribe. Both Antoine and Son Child are bilingual and both frequently act as translators in the disputes between their kinsmen and the white world regarding the dam and Cooke's death. In this way, Son Child and Antoine embody McNickle's conception of permeable "ethnic boundaries," developed in his treatise Native American Tribalism, which eschews essentialized notions of Native identities and argues that cultural change is necessary for Native America to survive as a distinct entity (McNickle 1973, esp. chap. 1).

In Wind, the act of journeying between worlds imparts the wisdom necessary for the tribe's survival, illustrating McNickle's conviction that Natives must cultivate the ability to negotiate changes brought about by the dominant culture. ${ }^{9}$ Significantly, all of the story's anticolonial characters repeatedly cross various cultural or epistemological borders. The wise man and dreamer of the tribe, aptly named Two Sleeps (his name, like that of Son Child/The Boy, carries a double valence signifying his ability to see the world in different ways), had come to the Little Elks from another tribe. They found him in a death-like state after other members of his family had been murdered. Throughout the story, it is in the realm between sleep and waking that Two Sleeps receives his visions and gives guidance to the Little Elk people. Son Child, too, is a character who traverses worlds in multiple ways. Not only does he journey between cultures, but his name also links him to the character of Thunderbird, child of the Sun, a figure who is both mythical and human and whose story occupies an important place in the novel. Like Son Child, Antoine, whose father is associated with the sun, bears a relationship to Thunderbird. As the novel relates the story, Thunderbird was born into the Little Elk tribe and empowered the Indians to resist their enemies with his spiritual gifts of tobacco and a medicine bundle. Part of his power derived from the fact of his hybridity, as well as his ability to travel between the world 
of the sun and that of earthly beings. McNickle implies that characters like Thunderbird, characters who can move between worlds, similarly have the power to help the tribe in the present crisis precipitated by clashing cultures. Unlike colonialism's agents, these border-crossers actually participate in the Native and European American worlds, rather than governing from the outside or otherwise refusing to engage difference. Unlike colonial maps of the mind, then, this anticolonial map is functional rather than essential. Its aim is not to fix the world in an image remarkable like its own. Rather, it attempts to engage diversity as a means of survival and growth, producing multiple images that overlap, interact, and change.

Importantly, however, while this third map originates in the Little Elk world, in Wind from an Enemy Sky neither hereditary race nor culture completely determines which map of the mind the characters will follow. This point underscores McNickle's insistence that cross-cultural knowledge is essential to effective political resistance. In this case, characters (even colonized subjects) who fail to understand the logic of colonialism are doomed to repeat it. Bull, leader of the Little Elk tribe, for example, acts in accord with colonial culture's first map of the mind by consistently demonstrating inflexibility and epistemological blindness to the difference of European American culture. The nature of Bull's character becomes manifest in the novel's opening pages. If the dam violates the sacredness of the valley in the opening scene, so, too, does Bull's violent reaction to the structure. While the site was a place of power, Bull defies the prohibitions surrounding it by immediately becoming enraged upon viewing the dam and foolishly shooting at the structure. Significantly, at this very moment, he intuits the nature of its maker, the quintessential colonial figure Adam Pell-the engineer, financier, and collector who built the dam-even invoking his name (his reference to "first man" points to the Biblical Adam): "Who is this creature who built that thing of rock and stopped the water? Is he two-legged like other men? Or is he a monster first-man, who decides things in his own way?" (1995, 7). But Bull is also a man who "decides things in his own way." Since the arrival of white settlers in Little Elk territory, he had refused to engage them in any way. He had also helped turn the tribe against his own brother, Henry Jim, when Henry Jim began to adopt white ways. In fact, at the beginning of the novel, it is Bull's inappropriate actions, as much as it is the building of the dam, that lead to the murder of Jimmy Cooke (who, we learn, is Pell's nephew). In shooting Cooke, Pock Face merely follows in the footsteps of his uncle, imitating his own violent reactions to the dam's construction. Born in colonial violence, Bull's destructive character, the product of his intolerance for difference, both mimics colonial culture's hegemonic impulses and testifies to its power to recreate Indians in its own image.

It is, in part, Bull's intractability and domineering ways (his adherence, in other words, to the first map of the mind) that drive McNickle's story to its catastrophic conclusion. As the narrative progresses and both parties begin to come 
to terms with the killing of Cooke, the prospects for refiguring Indian-white relations appear strong. Times, it seems, have changed. Bull, who had always refused to engage the white world, begins to trust the Indian agent Rafferty, and indeed the agent seems genuinely committed to the interests of the Indians. The wedge driven between the two groups by colonialism's devastations appears to be dissolving when the tribe seeks Rafferty's aid in recovering the medicine bundle. Rafferty follows through on his promises to help and traces the bundle to Adam Pell's significantly named Americana Institute. Pell's role as collector illuminates another critical dimension of his character. His collecting parallels his building of the dam on Little Elk land: both activities involve appropriating resources essential to Little Elk life (a crucial aspect of American colonialism). But his collecting is important in another respect as well. By locating what is valuable in Native life in objects from the past, he denies (as does Rafferty) a viable role for Native peoples in the present. In this way, too, he is like Bull: both characters refuse to recognize and adapt to historical change, a tendency with devastating results. In fact, when Pell attempts to recover the medicine bundle, which had been consigned to a lumber room in the museum's basement, he makes a "monstrous discovery." The language here evokes the history of discovery and conquest, and the action points to its terrible consequences. The "battle museums wage against rats, moths, [and] organic decay ... had caught up with the medicine bundle," leaving it "tattered and profaned, devoid of holy mystery" (1995, 210). This event points to the double logic of colonial culture, which consigns Native peoples either to a "progressive" present, in which Natives must assimilate into colonial culture (and, in so doing, cease being Native), or to an unchanging past (by "museumizing" them, a tendency of both Bull and Pell). By metonymically linking the fate of the bundle with that of the tribe, McNickle alludes to the fate of Native peoples governed by white institutions.

Exhibiting once again his intractable blindness, in an effort to vindicate himself for the destruction of the bundle, Pell absurdly decides to replace it with the "Virgin of the Andes," a priceless (in monetary terms) gold figure that had been for many years the collector's obsession. Pell had traveled the globe in his quest for the figure, ultimately parting with a vast sum to acquire it. This action, which fails to recognize the culturally specific meanings of different objects, further embodies and shows the failure of the first map of the mind. Cut off from the cultural context that gave it meaning, though, "its only present value was as a piece of merchandise" (213). The object, in other words, had been "translated" into a new framework that obliterated its original significance. His behavior here replicates the workings of colonialism throughout the book, which attempts to annihilate difference by universalizing European American ways. Pell's gift-a paternalistic gesture - constitutes yet another act of assimilation, an attempt to bring the Indians into the world of capitalism and "progress." But there is another key aspect of Pell's gift, and herein lies the crux of the catastrophe. In this regard, its physical features comprise a good part of its significance: 
The modeling of the nude figure was skillful, combining accurate proportioning with expressive detail. The adolescent body was clearly portrayed-breasts just swelling, hips just emerging, the vaginal cleft slightly mounded, childish plumpness forming into rounded curves - but above the torso was the face of a mature woman, staring calmly out of almond-shaped eyes. (213)

In addition to its newly acquired commodity value, several things about the figure are important. First, it is the figure of an adolescent, a fact that resonates with colonial culture's infantilizing of Native peoples (signified in the text by the translation of the adult Son Child's name as "The Boy"). Second, it is the figure of a female with accentuated sexual features. The male collector's possession of her to the exclusion of others (he does not display her, but instead wraps her in black velvet and locks her in a walnut case) thus comprises a sexualized relationship that resonates with the violence and possession of colonial conquest. What Pell decides to present to the Little Elk Indians is, in other words, a mirror image of themselves and their own subjection to colonial power.

Pell's decision to replace the medicine bundle with the statue is as absurd as it is inevitable. To Pell, Indian objects are Indian objects, equivalent elements in the conception of humanity that organizes people and culture in terms of their progress to civilization. Faced with the demand to restore the bundle, Pell believes the statue "will do," that the Little Elk will see no differences because, in his mind, there are none. The resulting disaster that follows Pell's decision is the logic of colonialism applied. Just as Frege's attempt to formalize arithmetic failed of its own logic, so Pell's conception of Native people as part of a single history of humankind was bound to fail of its own efforts and to carry devastating consequences.

In the novel's final scene, when the Little Elk people learn of the destruction of the medicine bundle and Pell unsuccessfully attempts to give them his gift of the gold figure, disaster erupts. This disaster points to the inherent failure of both colonial approaches to mapping. The Little Elk people revolt at Pell's conception of them, and the illusions of the reciprocity and good faith of their relationships with Rafferty shatter. Acting in a response that harks back to the novel's beginning, Bull shoots the two colonial agents on the scene, Pell and Rafferty, killing both men. Bull kills Pell for his attempt to universalize his own world view, which is shown by the construction of the dam and his collecting of Native culture. But there is another important aspect of this scene: it reveals the destructive nature of Bull's character, specifically his failure to adapt to historical change, a tendency that parallel's Pell's simultaneous attempts to museumize and to assimilate Natives. Thus, the suicidal elements of his character, a kind of fatal self-reference, make him turn to the others left in the circle. As if to admit his failure, Bull then turns to Son Child, awaiting the bullet to the heart he knew would come. Just as Pell, the quintessential colonial figure, must die, so too must Bull perish. McNickle's violent condemnation pictures both a theoretical assess- 
ment of the logic of colonialism and its manifestation in the lives of subjugated Native peoples. Bull's and Pell's behaviors, which show the consequences of the first map of the mind in McNickle's novel, are two sides of the same coin, and both spell death for the Natives.

Rafferty's death at the hands of Bull similarly marks the failure of the second map of the mind and its limited attempt to avoid the problems of colonialism. As McNickle's narrative makes clear, the failure of benevolence and patronization is as inevitable as the failure of the map that guided Pell and Bull. Even as Rafferty struggled to grant value to the Little Elk people and their culture independent of their place in human "progress," he failed to acknowledge their agency. Ultimately, it is Rafferty who convinces Pell not to tell the Indians of the destruction of the medicine bundle, believing to the end that he understands the Little Elk well enough to make decisions on their behalf. In the end, Rafferty dies for clinging to his status as a powerful outsider and giving no voice to those he would govern. He dies, in short, because he, like Pell and Bull, cannot break free of the colonial logic that shapes the relations between European America and Native America.

But hope is not lost in this final catastrophic scene. The survivors of the shooting follow McNickle's third map of the mind, and herein resides the possibility for resisting colonialism and restoring Native sovereignty. Those who remain on the scene are Son Child/The Boy, Antoine, and the agency's European American physician, Doc Edwards. Significantly, the Little Elk characters Son Child/The Boy and Antoine are figures who have made the epistemological journey Bull would not (and, perhaps, because of his monocultural experience, could not) undertake successfully. Unlike Bull, who is mired in the past and unable to adjust to a changing world, Son Child and Antoine remain part of the Little Elk community while incorporating the new skills and creating the relationships that will enable them to survive in a changing world. Maps for them become a means of survival, a means of negotiating the unstable boundaries of cultural difference and historical change. When Pell reveals the fate of the bundle, they are already familiar with the workings of the white world, and so they do not experience the surprise that compels Bull's destructive action. Another survivor, Doc Edwards, provides a model for those non-Natives who would reject the colonial map of the mind. Unlike Rafferty, Edwards eschews official authority over the Indians, and he relies on the Indians' judgment in attending to their own affairs (the advice he gave to Rafferty, but the agent was unwilling to accept). He thus resists the logic of the colonial maps and their twin impulses to force Indians to assimilate or to consign them to a timeless and unchanging past. The abilities to adapt to change and to engage difference embodied in the anticolonial map of the mind, McNickle implies, guarantee the survival, not only of cultural diversity, but also of the inhabitants of both the European and Native worlds.

By contrast, the maps embodied by Bull, Pell, and Rafferty, despite their differences, share a common commitment to the kind of mapping that has the power to fix its objects permanently, in this case, to define Native culture in perpetual 
and fixed opposition to European America. All three die in part because they are each incompatible with survival and self-determination. The survivors and the processes of mapping they embody stand as an alternative way of engaging the world, not because they are more powerful, but because they give up the power to define and govern Native people. Rather, as border-crossers, they continually challenge the fixed nature of and relations between cultures pictured by these colonial maps. At the same time, however, they maintain "ethnic boundaries" wherein "Indians remain Indians not by refusing to accept change or to adapt to a changing environment, but by selecting out of available choices those alternatives that do not impose a substitute identity" $(1973,10)$. Maps for these characters become a means of survival, a means of negotiating the unstable boundaries of cultural difference and historical change. Maps conceived in the context of colonialism, maps of static peoples in a static world, are decisively rejected by Antoine, Son Child, and Doc Edwards in favor of a process of dynamic interaction where maps are aids rather than ends.

Even as Russell's paradox and its literature support a reading of McNickle's book, McNickle's work also can be read back into contemporary AngloAmerican philosophical discussion. ${ }^{10}$ On our interpretation, Wind from an Enemy $S k y$ presents an alternative approach to Russell's paradox that plays out the implications of the dominant ways of thinking about the world articulated in European philosophy and culture. Knowledge, McNickle instructs, can never be fixed or complete, and knowledge gained from the outside is particularly vulnerable to errors that result in violence. The novel also offers a model of an alternative map of the mind, or, rather, a way of mapping that can provide both a beginning to a new philosophical investigation of colonialism and recognition of the relevance of Native American thought to contemporary philosophical discourse. Wind from an Enemy Sky carries important lessons for anticolonial movements as well. Through the character of Bull, McNickle demonstrates the dangers of relying exclusively on tradition and retreating from the modern world. Native cultural survival, he argues, relies on adapting to changing circumstances without assimilating into the colonizing society. Like Son Child and Antoine, those who wish to survive clashing cultures must learn to negotiate contending worlds. The only alternative, he insists, is catastrophe.

\section{Notes}

1. McNickle (1904-77) numbers among the most prominent political and literary figures of the twentieth century. A cofounder of the pan-tribal National Congress of American Indians, member of the Bureau of Indian Affairs (BIA) under John Collier during the reformist 1930s, and lifelong activist, McNickle left a substantial mark on Native politics-past and present. In addition, his literary talents remain unsurpassed by the most accomplished and widely read Native writers. The author of three remarkable novels (the first of which, The Surrounded, was published in 1936), a handful of short stories, three works of history, and a biography, McNickle painted complex portraits of contemporary Native life beleaguered by colonial officials (both ill-willed and well-meaning) who wrest self-determination and, consequently, dignity and hope from their subjects. For information on his life, see The Legacy of D'Arcy McNickle (Purdy 1996) and Singing an Indian Song (Parker 1992). 
2. McNickle began writing Wind from an Enemy Sky in the 1930s, but the novel was published in 1978, shortly after the author's death.

3. See Meek (1976) and Sheehan (1974) for discussions of the role of the "stage theory" of human development in science and governmental policy.

4. By the beginning of the twentieth century, efforts by Giuseppe Peano and others to axiomatize arithmatic provided the starting point for the more ambitious efforts of Russell and Whitehead to axiomatize all of mathematics in terms of mathematical logic. Despite the implications of Russell's paradox, philosophers (especially the influential philosophers of the Vienna Circle) embraced the idea that increasingly complete knowledge of the world could be achieved from an observer's perspective using an axiomatized system, what Frederick Suppe has called "The Received View." This "Received View" came to dominate the philosophy and practice of science and social science. See Frederick Suppe's useful summary of the development and implications of this view in The Structure of Scientific Theories (1977, 3-232).

5. This is a rather explicit reference to the work of John Collier, head of the BIA during the 1930s. McNickle worked for a time at the BIA under Collier's supervision.

6. Russell originally presented the paradox in The Principles of Mathematics $(1903,101-7)$.

7. Quine develops this point in his paper "The Ways of Paradox" (1976a, 10-16).

8. Russell's conception strikingly parallels developments in early twentieth-century anthropology. Boas's commitment to cultural relativism eschewed the universalizing tendencies of Morgan's theories of social evolution, until then the dominant school of thought about the relations between cultures. At the same time, Boas's tendency to examine cultures in isolation and to relegate "primitive" cultures to the historical past articulated the colonial authority of the ethnographer while it obfuscated contemporary political relations between societies. In effect, while Boas rejected a universal perspective, he nevertheless maintained the possibility and value of mapping Native peoples from the outside. See, for example, Boas, Race, Language, and Culture (1940), and Morgan, Ancient Society, or Researches into the Lines of Human Progress from Savagery through Barbarism through Civilization (n.d., [1877]).

9. See McNickle's discussion of the Rough Rock school in Native American Tribalism (1973, chap. 7).

10. The connection between McNickle's narrative and the limitations of European and European American logic is clarified by Dewey in his 1938 critique of Anglo-American logic entitled Logic: The Theory of Inquiry. Replying directly to Russell's paradox, Dewey argues that the paradox is generated when the character of concrete mapping is set aside. The contradiction alleged to exist, Dewey says, arises only when the existential and the conceptual are confusedly identified $(1938,362)$. The problem emerges for logicians when they forget the lived experiences out of which ways of thinking arise. When experience and theory are rejoined, mapping can be seen as part of the pursuit of desired ends. From this perspective, maps are no longer more or less successful efforts to describe the world completely, but more or less successful efforts to engage the world. On the functional interpretation, Dewey concludes, any map in any system is valid if its operational use produces the consequences that are intended to be served by the map (399). Recalling McNickle's narrative, Dewey's conclusion cuts two ways. On one hand, the alternative approach to mapping provides a flexible resource in service of the goal of Native cultural survival. It identifies the features of the territory necessary to avoid the dangerous places, to locate food and water, and to find shelter. On the other hand, it is a critical tool that can challenge colonial power by uncovering its ends and tracing the connections between maps and cultural destruction. In the end, by narrative, McNickle goes beyond the formal response by Dewey and provides both a critique of the logic at work and an illustration of the concrete implications of colonial maps on the lives of Native people. From the perspective of our discussion, once the connection is recognized, Russell's paradox becomes a valuable locus of investigation where philosophers can reconnect abstract reflection to the living issues of colonialism and cultural survival. 


\section{Works Cited}

Boas, Franz. 1940. Race, Language, and Culture. New York: Macmillan.

Dewey, John. 1938. "Logic: The Theory of Inquiry" In The Later Works, 1925-1953, Volume 12. Ed. Jo Ann Boyston. Carbondale, IL: Southern Illinois University Press. 1991.

McNickle, D'Arcy. 1973. Native American Tribalism: Indian Survivals and Renewals. New York: Oxford UP.

1995. Wind from an Enemy Sky. Albuquerque: $U$ of New Mexico $P$.

Meek, Ronald L. 1976. Social Science and the Ignoble Savage. Cambridge, UK: Cambridge UP.

McNickle, D'Arcy. 1966. “The Indian Tests the Mainstream,” In The Nation, 203 (September 26): 275-279.

Morgan, Lewis Henry. [1877] n.d. Ancient Society, or Researches into the Lines of Human Progress from Savagery through Barbarism through Civilization. Chicago: Charles H. Kerr.

Parker, Dorothy R. 1992. Singing an Indian Song: A Biography of D'Arcy McNickle. Lincoln: U of Nebraska P.

Purdy, James, ed. 1996. The Legacy of D'Arcy McNickle: Writer, Historian, Activist. Norman: U of Oklahoma P.

Quine, W. V. O. 1976a. "The Ways of Paradox." In Quine 1976b, 10-16. . 1976b. The Ways of Paradox and Other Essays. Rev. ed. Cambridge, MA: Harvard UP.

Russell, Bertrand. 1903. The Principles of Mathematics. Cambridge, UK: Cambridge UP. 1919. Introduction to Mathematical Philosophy. New York: Macmillan.

1956. Logic and Knowledge: Essays, 1901-1950. Ed. Robert Charles Marsh. London: Macmillan.

Sheehan, Bernard. 1974. The Seeds of Extinction. New York: Norton.

Suppe, Frederick. 1977. The Structure of Scientific Theories. 2d ed. Urbana: U of Illinois P. 